\title{
"TORTILLA MIT SAUERKRAUT"
}

\section{UNA DIDACTIZACIÓN DE LOS MALENTENDIDOS INTERCULTURALES}

$\mathrm{T}$ odo empezó con el bonito proyecto de Paco Zayas de la Universidad de Cádiz para el mAGAzin eXtra7, Comic im Unterricht, ya editado (Información y pedidos: anke.berns@uca.es).Paco nos dió a los posibles colaboradores unas instrucciones prolijas y muy concretas: idear situaciones de malentendidos culturales de una familia española en Alemania y didactizarlas mediante un guión de cómic y la correspondiente unidad didáctica.

Pero me dí cuenta que desde luego yo mismo no era la persona más indicada para relatar las experiencias de un español en Alemania, puesto que mi caso es el inverso. Antes que ponerme a imaginar tales (des)encuentros, preferi recurrir a las personas que realmente habian experimentado ese choque cultural: mis estudiantes de cuarto curso del Instituto de Idiomas de la Universidad de Sevilla, pues alrededor de la tercera parte de ellos había estado en un país de habla alemana, los más con una beca Erasmus. Así que decidi aprovechar ese estupendo caudal de experiencias para convertir a los estudiantes en diseñadores de material didáctico para otros estudiantes.

Esta unidad didáctica, por un lado, tiene sentido por sí misma: presenta variedad de actividades verbales y no verbales, variedad de formas de organización social y un producto final divertido y creativo. Pero, por el otro lado, también puede servir para seguir engrosando ese acervo común de experiencias interculturales mediante una sección en la página-web del AGA, en la que se podrían "colgar" las historietas escaneadas, con los dibujos originales de los estudiantes.

\section{LA UNIDAD DIDÁCTICA}

Nivel: a partir de B1, Grundstufe 5-7, (Zertifikat Deutsch) Duración: 90-120 minutos

Material: rotuladores, transparencias, hojas DinA3.

\section{Contextualización}

Se ofrecen distintas alternativas:

- Asociograma "Typisch Deutsch?",

- Elaboración de listas de frases que empiezan con "Die Deutschen sind ...." oder "Die Deutschen (Verb)...", en orden alfabético ("Die Deutschen arbeiten viel, Die Deutschen sind oft blau etc.), en grupos de cuatro.

- Visionado del documental didáctico "Typisch deutsch", cap.18, "Deutschland - Außenansichten", en Einblicke. Ein deutscher Sprachkurs, GoetheInstitut Inter Nationes.

\section{Desarrollo}

El desarrollo corresponde a las actividades propuestas en la hoja de trabajo, en la página siguiente.

En la actividad de relatar las experiencias interculturales (1.), los grupos se reparten de modo que en cada una haya al menos una persona con "experiencia alemana".
Christoph Ehlers

Instituto de Idiomas

Universidad de Sevilla

En la presentación de la familia Rodríguez (pág.2) se ofrecen varias posibilidades: p.e. - Dividir la clase en 2 grupos, un grupo lee las descripciones de los padres, el otro de los niños. Luego se emparejan dos estudiantes de cada grupo y se relatan sus personajes.

- Asignar las imágenes a los textos, a los que se le quita los nombres propios y la edad

\section{Fase de Consolidación}

Mientras en la fase de desarrollo las actividades verbales de los estudiantes consisten en las narraciones de sus experiencias, la recepción del texto de la familia Rodríguez y la negociación sobre el contenido y diseño de la tira de cómic (ésta última especialmente activa), los alumnos ahora proceden a presentar sus resultados, los dibujos sobre la transparencia, ante el pleno.

En esta fase, se emplean las mismas técnicas didácticas previstas para el trabajo con las tiras ya elaboradas:

- Se tapan las imágenes, dejando sólo el título. En el pleno se hacen hipótesis sobre el contenido de la tira - Las imágenes se van descubriendo una a una, siempre después de formular hipótesis sobre el contenido de la imagen siguiente.

Al final los autores relatan su propia experiencia en la que se basa el cómic de los Rodríguez.

Como actividad de consolidación fuera del aula, se ofrece también la narración por escrito de las anécdotas interculturales vividas o la elaboración de guiones para las situaciones que no habían sido escogidas para el cómic en clase. 
Servietten auf dem Boden...Laute Weihnachten...Pünktlichkeit...Wasser mit "Gas" - Wer kennt sie nicht, diese kleinen Details, die ein Land vom anderen unterscheiden? Diese kleinen kulturellen Unterschiede sind Thema eines Mini-Projekts, in dem wir aus euren eigenen interkulturellen Erfahrungen und Anekdoten von euren Aufenthalten in den deutschsprachigen Ländern eine Reihe von Comic-Strips machen möchten. Die Hauptfiguren in diesem Comic seid nicht ihr, sondern die Mitglieder einer "typischen" spanischen Mittelklassefamilie, die Rodríguez, die für ein Jahr nach Deutschland zieht und dort viele Überraschungen erlebt.

\section{Erzählt euch bitte in Kleingruppen eure interkulturellen Erfahrungen und vor allem Missverständnisse in D-A-CH.}

- Wer von euch war schon einmal in D-A-CH?

- Was habt ihr da gemacht?

- Wo? Wann? Wie lange? Warum? Mit wem?
- Gab es Dinge oder Situationen,

- die euch überrascht haben?

- die ihr komisch fandet?

- an die ihr euch gar nicht oder nur schlecht gewöhnen konntet?

- die euch vielleicht gestört haben?

- oder über die ihr lachen konntet?

\section{Schreibt hier die Erfahrungen und Anekdoten in Stichworten auf}

1.

\section{DIE FAMILIE RODRÍGUEZ}

Es handelt sich um eine "typische" spanische Mittelklassefamilie (Vater, Mutter, Großmutter und 3 Kinder), die wegen Papis neuem Job für ein Jahr in Deutschland sind. Keiner von ihnen spricht am Anfang auch nur ein Wort Deutsch. Papis Aufgabe: Bankfilialen in ganz Deutschland besuchen und deutsche Organisation und Effizienz lernen.

Vater: José María, 47 J., Anzug- und Krawattenträger, Kettenraucher, gemütlicher Typ (Lieblingsessen Tortilla, Bierchen mit Freunden am Zahltag, Fußballfan...). Seine spanische Bank ist von einer deutschen geschluckt worden, und jetzt soll er deutsche Arbeitsweisen in situ kennen lernen. Von seinem Deutschlandaufenthalt verspricht er sich phantastische Aufstiegschancen in Spanien. Er besitzt ein großes Impovisationstalent, das von seinen Chefs als Intelligenz missverstanden wird.

Mutter: Milagros, $45 \mathrm{~J}$. Als Mädchen Sekretärinnenschule, dann Bank, wo sie Papi traf. Dann drei Kinder. Schwächen: Zellulitis, dominant und sehr eifersüchtig, shoppen, Look ihres Mannes. In Deutschland versteht sie plötzlich, was "Emanzipation" heißt, und versucht nun, die Familie neu zu organisieren.
Der älteste Sohn: Alberto, 19 J. Sehr eitel und sich seiner Wirkung auf Frauen bewusst. Er ist überzeugt, dass die deutschen Mädchen ihm zu Füßen fallen werden. Geht als Gasthörer zur Uni. Er steht auf Musik, Klamotten und Partys. Typisch spanisch: er kann sich noch nicht einmal ein Spiegelei machen.

Die Tochter: Inés, $15 \mathrm{~J}$. Sie ist etwas unordentlich,
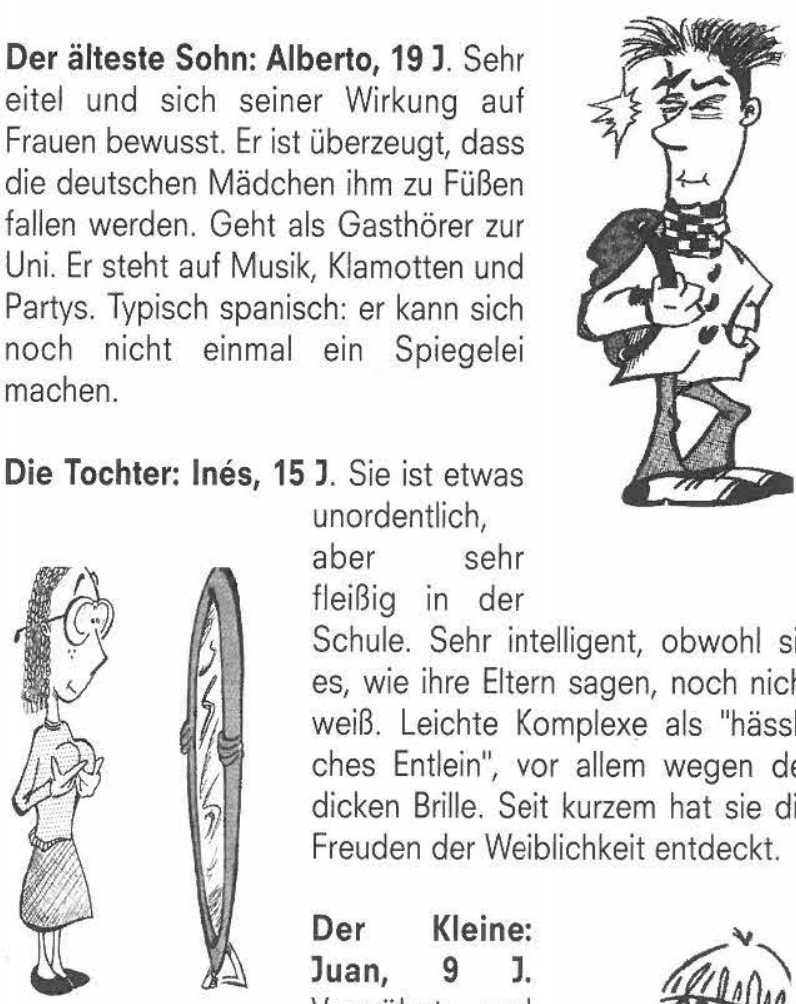
aber sehr fleißig in der Schule. Sehr intelligent, obwohl sie es, wie ihre Eltern sagen, noch nicht weiß. Leichte Komplexe als "hässliches Entlein", vor allem wegen der dicken Brille. Seit kurzem hat sie die Freuden der Weiblichkeit entdeckt.

$\begin{array}{ll}\text { Der Kleine: } & \\ \text { Juan, } 9 & \text { J. } \\ \text { Verwöhnt } & \text { und }\end{array}$ launisch. Omis Liebling. Gehorcht nicht und lügt viel. Leidenschaften: Fussball, Motorräder und Skate-Board, mit dem er die Bürgersteige terrorisiert. Isst sehr viele Süßigkeiten und ist ein schlechter Schüler

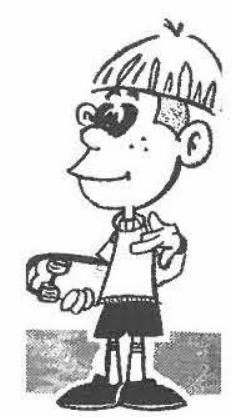




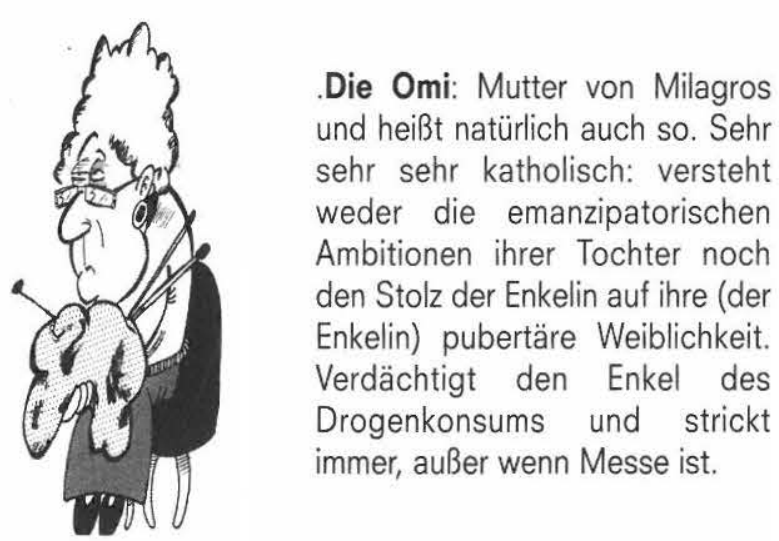

Unten und rechts: zwei der Comics, die von den Schülern des Vierten Kurses am Fremdspracheninstitut Sevilla im Unterricht ausgearbeitet und präsentiert wurden.

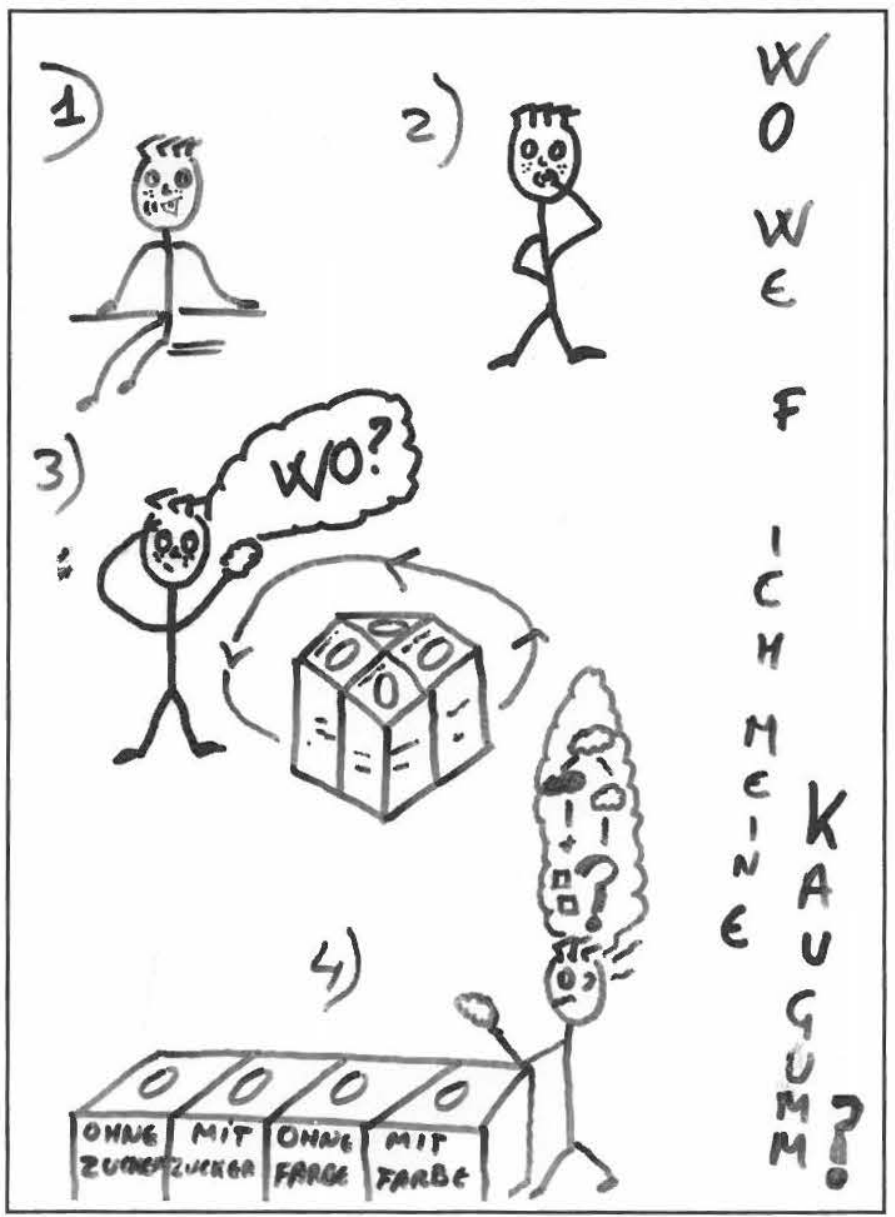

Der Hauptakzent liegt auf den kulturellen Unterschieden und den sprachlichen und kulturellen Missverständnissen. Mögliche Situationen gibt es jede Menge, zum Beispiel:

Papi: auf Geschäftsreise -Fahrkartenkauf - Speisewagen Bankzweigstelle - Geschäftsessen (zB "Lüngeln" oder "Milzwurst"; plötzlich setzt sich einfach jemand an seinen

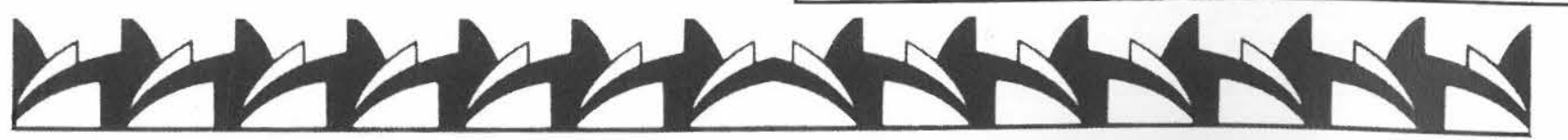

Tisch; diskutiert mit der Klodame den Preis; versteht das mit dem "Trinkgeld" nicht...)

Mami: geht einkaufen (und findet keinen Chorizo oder muss die Plastiktüten bezahlen) - zum Frisör - ins Frauenzentrum Alberto: jede Menge Kneipen, Diskos, Demos... (man kann nicht einfach "ein Bier" bestellen, es gibt immer mindestens drei verschiedene Typen; das Zapfen dauert schrecklich lange; jeder bezahlt getrennt...)- Uni, Mensa - deutsche Freundin....

Inés: Enthaarungscreme kaufen (behaarte deutsche Frauen) - weibliche Geheimnisse geteilt mit ihrer besten Freundin deutsche Jungs auf Partys (komisch: auf dem Boden sitzen und quatschen statt wild tanzen)

Juanito: Unterricht in der Grundschule - Ausflug Abenteuer...

Omi: allnachmittäglicher Kirchgang - Wetterbericht im Fernsehen gucken....

3 Jetzt versucht bitte in der Gruppe, aus euren eigenen Erfahrungen in Deutschland einen kurzen Comic-Strip mit den Rodríguez zu machen (4-5 Bilder).

Die Struktur ist am besten: Einführung, Höhepunkt, Auflösung. Der Titel sollte vielsagend sein. Und es sollte immer nur ein Spanier präsent sein, damit der Gebrauch der deutschen Sprache authentisch ist.

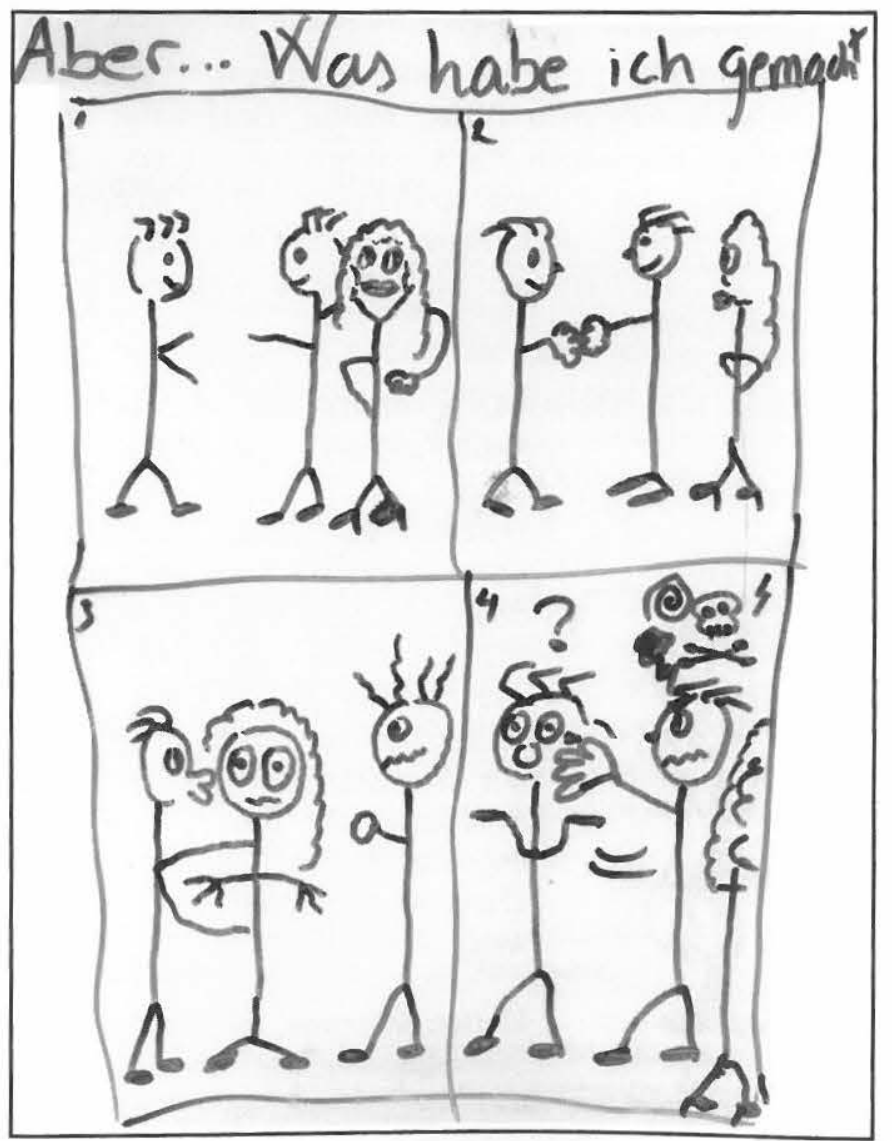

